\title{
Experimental study of Scour around a complex pier with elliptical pile- cap
}

\author{
Priyanka Gautam \\ Ph.D. Research Fellow, Department of Civil Engineering, Indian Institute of Technology Bombay, India
}

T. I. Eldho

Professor, Department of Civil Engineering, Indian Institute of Technology Bombay, India

M. R. Behera

Assistant Professor, Department of Civil Engineering, Indian Institute of Technology Bombay, India

\begin{abstract}
A complex bridge pier is an assembly of a column and foundation such as pile foundation with a pile-cap, partially or completely exposed to the flow. Considering the interaction of various factors around the pier, the pile-cap elevation in relation to the sand bed is expected to differ with time. Therefore, it is necessary to assess scouring over various potential pile-cap elevations. In this paper, laboratory experiments were carried out to analyze scour and mean velocity profiles around complex pier under the effect of low Reynolds numbers. Three pile-cap elevation cases were studied here, viz, the sand bed depth taken above the pile-cap level; the sand bed depth taken below the pile-cap top; and the sand bed depth taken at the level of pile-cap bottom. The results showed different scour patterns in the three cases considered. It was also noted that the least scour-depth occurred in the second case and maximum in the first one.
\end{abstract}

\section{INTRODUCTION}

A complex bridge pier is an assembly of bridge foundation consisting of a pier column built on a pile-cap or footing, supported by a number of piles (Coleman, 2005). Because of its physical and financial considerations, they are more preferred to be constructed in rivers these days. Over its lifetime, the different components of a complex pier gets revealed to the flow because of varying amount of sand aggradation or degradation around the pier assembly. Hence, it becomes necessary for the engineers and hydraulicians to know what change in vortex pattern is caused as a result of the varying pilecap depth relative to the sand bed depth, and hence the scouring around it.

The complications in the local scouring process at complex bridge pier locations are because of the interaction of flow structures (i.e., down flow and horseshoe vortex) with the three components of the complex pier, generating new vortex structures, as witnessed by Beheshti and Ataie-Ashtiani (2010). This augments to the difficulty in predicting local scour depth at these complex pier structures.

Research on scouring at complex bridge piers is comparatively newer than on single uniform piers, with lesser number of studies present in the literature and thus demanding additional research on the flow changes occurring around complex bridge piers (HEC-18, 2001). Few studies have been done for the calculation of local scour-depth (e.g. Melville et al., 2006; Akib et al., 2014) and few for investigating the flow patterns around a complex bridge pier structure (e.g., Beheshti and Ashtiani, 2010; 2016), mostly with rectangle shaped pier and pile-cap or rectangle with round ends.

Beheshti and Ashtiani (2010) investigated the three-dimensional turbulent flow field around a rectangular complex bridge pier (with rectangular pilecap) placed on a fixed rough bed with the aid of experiments. In their setup, they exposed all the components of the pier (column, pile-cap and piles) to the incoming flow. They found out the governing features of the flow around the pier which are responsible for the scouring process around a complex pier. The main reasons being the constricted flow below the pile-cap and towards the piles, a strong downward flow along the sides of the pile-cap in the upstream region of the pier and a vortex flow behind the pile-cap.

Few researchers have conducted experiments to study scour around complex bridge piers, with varying shape of the pier structure, flow conditions as well as at different pile-cap elevations. Melville et al. (2006) gave a methodology to predict local scour depth at a complex pier to identify the relative scouring capacity of the various components of complex piers and the evolution of scouring phenomenon occurring for variable pile-cap elevations. Ferraro et al. (2013) performed experimental tests on scour around complex bridge piers of different arrangements for studying the influence of pile-cap thickness on the temporal development of maximum scour-depth. Akib et al. (2014) presented an experi- 
mental study focusing on the relationship between scour depth in complex pier groups and combined piles bridge and various factors including the variation of inflow velocity, distance, and time. Moreno et al (2015) carried out experimental campaign to study three complex bridge pier models (rectangular shape of pier with round ends) under steady state, clear-water flow conditions. They assessed the effect of relative column and the pile-cap widths on equilibrium scour depth in three different situations, viz, when the pile-cap was above the sand bed (Situation 1), partly submerged in the sand bed (Situation 2), and completely buried in the sand bed (Situation 3).

Various conclusions have been made through the experimental findings of the aforementioned investigators. Ferraro et al. (2013) found out that greater the thickness of the pile-cap, the deeper was the corresponding scour-hole. The thickness of the pile-cap also affected the temporal variation of the maximum scour-depth, depending upon the height of the pilecap with respect to the sand bed. Moreno et al. (2015) found out that the temporal variation of maximum scour-depth is affected by various factors, viz, pile-cap elevation pertaining to sand, relative column width (main column width to pile-cap width), pile-cap thickness and the geometrical shape of the various bridge pier components.

From the results obtained by Melville at al. (2006), they observed that the pile-cap elevation with respect to the sand bed may differ with respect to time, therefore, local scouring needs to be evaluated over an array of pile-cap elevations. So in this paper, a complex bridge pier structure with cylindrical main column and elliptical pile-cap is studied experimentally, with 3 different pile-cap elevations. The effect of using an elliptical shape of pile-cap is studied, assuming it may help in avoiding excessive scour around them because of its streamlined shape. The experiments were conducted under clear water conditions, with low Reynolds numbers. The time evolution of scour, equilibrium scour depth, scour patterns and mean velocity profiles around the complex pier were analyzed and are presented here.

\section{EXPERIMENTAL SETUP AND PROCEDURE}

The experiments were carried out in a horizontal, recirculating flume of length $8.4 \mathrm{~m}$, width $0.3 \mathrm{~m}$ and depth of $0.55 \mathrm{~m}$ in Hydraulics laboratory, Indian Institute of Technology (IIT) Bombay, India (Fig. 1). The sidewalls of the flume were made of transparent Plexiglas to facilitate visual observation of the flow. At the inlet section, a stilling ramp was provided for uniform entry of water into the flume consisting of a metallic grid and an ascending ramp with sand glued to its surface for damping the flow disturbances leading to uniform flow distribution. Required normal flow depth over the sand bed was achieved by a modifiable tailgate which was positioned in the downstream end of the flume. The water was lifted from the main reservoir to a constant head reservoir by pump. The flow rate was monitored using a Flow-meter attached to the feeder pipe from pump.

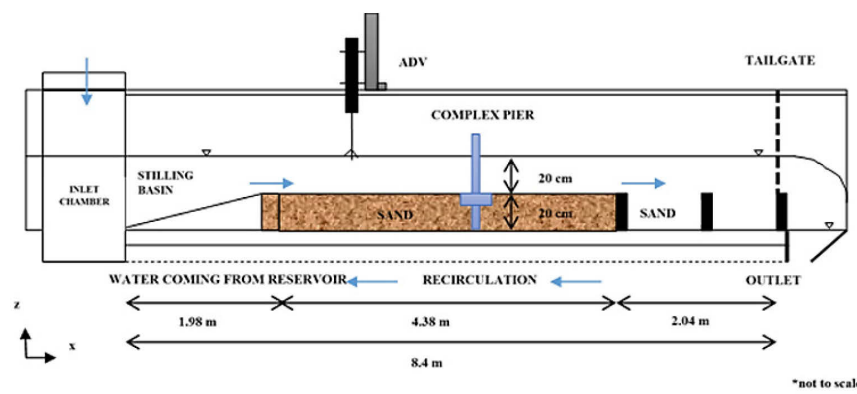

Figure 1. Schematics of the flume used for experiments.

A schematic diagram of the experimental setup is shown in Figure 1. A sand box (consisting of test section) of length $4.38 \mathrm{~m}$ was provided at a distance of about $2.0 \mathrm{~m}$ from the inlet. The location of test section was selected in such a way that the flow becomes uniform and fully developed as it reaches the test section. Non-uniform Quartz sand of median diameter $d_{50}=0.81 \mathrm{~mm}$. The geometric standard deviation or gradation coefficient, $\sigma_{g}\left(=\left(d_{84} / d_{16}\right)^{0.5}\right)=$ 1.431 (found after performing Sieve Analysis of the sand), was filled in the sand box. The relative density of sediment, $s$ was measured as 2.66 for the sample.

The complex pier model was placed centrally and vertically in the sand box, at a distance of $4.5 \mathrm{~m}$ from the water inlet of flume. A sand recess box of length $0.9 \mathrm{~m}$ was provided at a distance of $\sim 2.0 \mathrm{~m}$ from the pier location, to trap the eroded and transported sand and prevent settlement of sand in the water reservoir. (a).

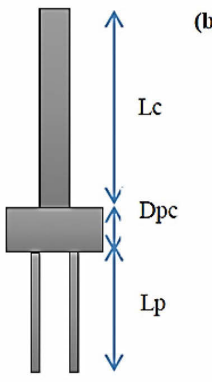

(b).

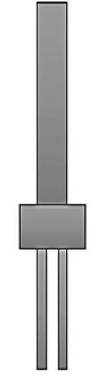

(c).

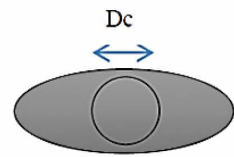

(d)

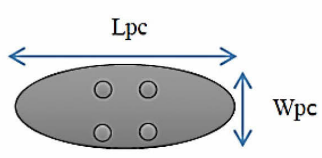

Figure 2. Geometric characteristics of complex pier: (a) side view; (b) front view; (c) top view; (d) bottom view.

The complex pier model was designed with a cylinder resting on an elliptical shaped pile-cap reinforced by an array of $2 \times 2$ piles (Fig. 2).

The diameter of the main column $\left(D_{c}\right)$ was taken as $3 \mathrm{~cm}$. Chiew and Melville (1987) recommended $B / b \geq 10$ ( $B=$ flume width) for single uniform piers 
of width $b$ so that the blockage effect of the pier becomes insignificant in pier scour experiments. For this study, the ratio $B / b=10$, ensuring negligible blockage effect. Rest of the definition of the parameters of complex pier and their dimensions are presented in Table 1.

Table 1. Complex pier definition and dimensions

\begin{tabular}{lll}
\hline Parameter & Definition & $\begin{array}{l}\text { Dimension } \\
(\mathrm{cm})\end{array}$ \\
\hline $\mathrm{L}_{\mathrm{c}}$ & Height of main column & 25 \\
$\mathrm{D}_{\mathrm{pc}}$ & Height of pile-cap & 5 \\
$\mathrm{~L}_{\mathrm{p}}$ & Height of pile & 20 \\
$\mathrm{D}_{\mathrm{p}}$ & Diameter of pile & 1 \\
$\mathrm{~L}_{\mathrm{pc}}$ & Length of pile-cap & 12 \\
$\mathrm{~W}_{\mathrm{pc}}$ & Width of pile-cap & 4 \\
\hline
\end{tabular}

The complex pier model was built using Acrylic rod and sheets and then painted for better observation under water. The complex pier was placed in the flume such that the longitudinal axis of the complex pier was in line to the approaching flow. For ensuring clear water conditions. Shen et al. (1969) suggested that the flume width should be at least eight times the diameter or size of the pier, which agrees well in the adopted experimental setup and pier model. For attaining clear-water conditions in the flume, the experiments were conducted for a number of discharge, viz, $0.009 \mathrm{~m}^{3} / \mathrm{s}, 0.012 \mathrm{~m}^{3} / \mathrm{s}$, $0.015 \mathrm{~m}^{3} / \mathrm{s}$ and $0.018 \mathrm{~m}^{3} / \mathrm{s}$. In this paper, results obtained from only the highest discharge are presented, having a flow intensity $U / U_{c} \approx 0.7$ ( $<1$ for clear water scour), where average flow velocity, $U=0.31$ $\mathrm{m} / \mathrm{s}$ and critical flow velocity, $U_{c}=0.44 \mathrm{~m} / \mathrm{s}$. $U_{c}$ was obtained from Shield's diagram (Miller et al., 1977).

After compaction and levelling of the sand, the pump was started initially with a very low discharge so that the flume gets filled up with water without any uncontrolled scour happening near or far from the pier model. Once the flume was filled with the required water depth, the discharge was increased to the required value. Local scour around the pier initiated immediately, which was carefully observed and noted.

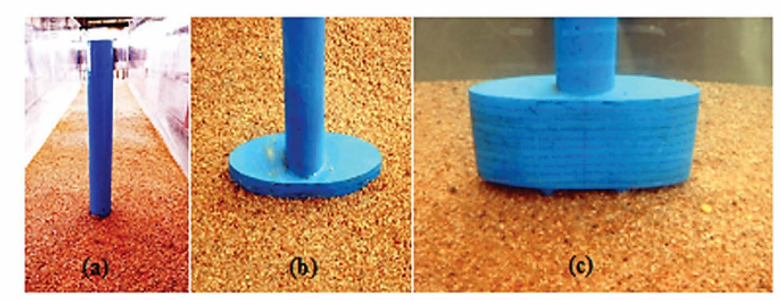

Figure 3. Photographs showing: (a). pile-cap buried in bed; (b). pile-cap partially buried in bed; (c). pile-cap resting on the bed.

For the purpose of evaluating scour and velocity profiles around complex piers, 3 pile-cap positions were tested. These pile-cap positions were selected to identify relative scouring potential of the various components of the complex pier.

The cases are shown in Figure 3, as follows:

1. Case (a) showing pile-cap buried in the sand bed (sand bed thickness over the pile-cap top being $5 \mathrm{~mm}$ );

2. Case (b) showing pile-cap exposed to the flow (pile-cap thickness exposed to the flow is $10 \mathrm{~mm}$ ); and

3. Case (c) showing pile-cap resting on the bed.

Each experiment was run for an average time duration of 9 hours. This duration was adopted after observing the time taken to achieve equilibrium scour depth around the piers. The magnitude of the maximum scour depth remained same, while the extent of the scour area increased in the third case, even after 9 hours. The 3D velocities were recorded using Nortek Acoustic Doppler Velocimeter (ADV). The Sampling rate was set at $50 \mathrm{~Hz}$. At the end of each experiment run, the water flow in the flume was slowly reduced, so as not to cause any change in the scour pattern obtained. After all the water got drained out of the flume, scour-depth readings were taken using a Vernier Point-Gauge.

\section{RESULTS}

\subsection{Temporal variation of scour}

The temporal variation of scour was measured at the point where the scour initiated (mostly the position of maximum scour-depth obtained). All the cases took almost 3-4 hours to reach the stage of equilibrium.

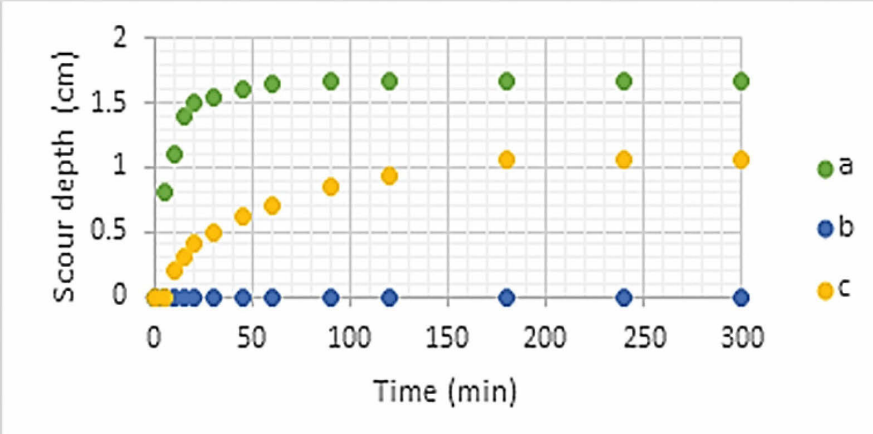

Figure 4. Comparison of temporal evolution of maximum scour depths for the 3 cases.

Figure 4 shows the comparison between the developments of maximum scour-depth as function of time for the 3 pile-cap elevations considered in the study. As evident from the figure, the temporal variation of maximum scour-depth is extremely diverse for the 3 different cases. Here the maximum scour- 
ing took place for case (a) (where pile-cap was buried in the sand), whereas for case (b), absolutely no scouring was observed.

It can also be observed that the maximum scour took place in the initial 50 minutes only, and after that, the scour started to stabilize, reaching equilibrium stage in almost 3-4 hours. In case (a), the scour depth increased rapidly in the first 30 minutes (until the pile-cap top got exposed to the flow ) and then it increased at a much slower pace, whereas, in case (b), the scour depth increased gradually for almost 3 hours and then it stopped.

\subsection{Scour patterns and Equilibrium scour-depth}

From the observations made after stopping the flow, it was clear that the pile-cap elevation (with respect to sand bed) holds an important part in the formation of scour-hole around the pier. The maximum equilibrium scour-depths for each case and their location are presented in Table 2.

Table 2. Maximum scour depth obtained for the 3 cases and their location of occurrence

\begin{tabular}{lll}
\hline Case & $\begin{array}{l}\text { Maximum scour depth } \\
(\mathrm{cm})\end{array}$ & $\begin{array}{l}\text { Location of maximum } \\
\text { scour depth }\end{array}$ \\
\hline $\mathrm{a}$ & 1.67 & Side of pile-cap \\
$\mathrm{b}$ & 0 & - \\
$\mathrm{c}$ & 1.05 & Tail of pile-cap \\
\hline
\end{tabular}

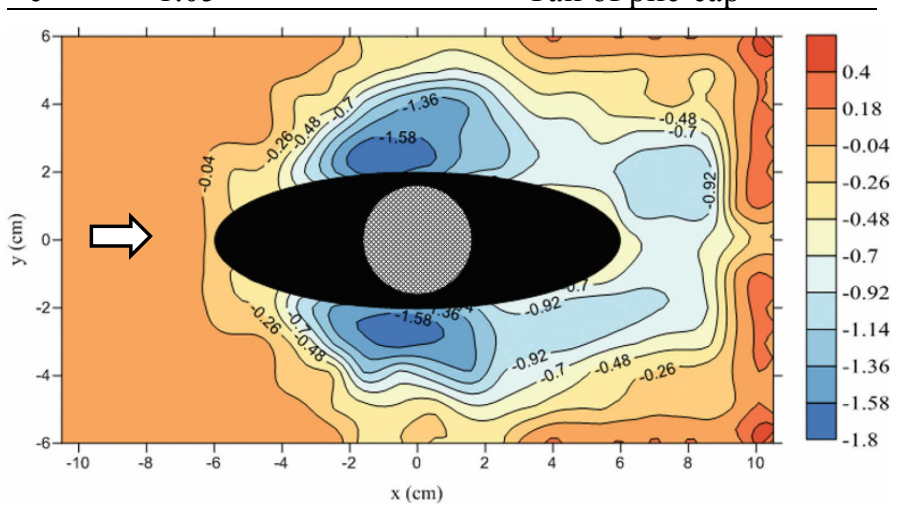

Figure 5a. Measured scour contours at equilibrium conditions for case a.

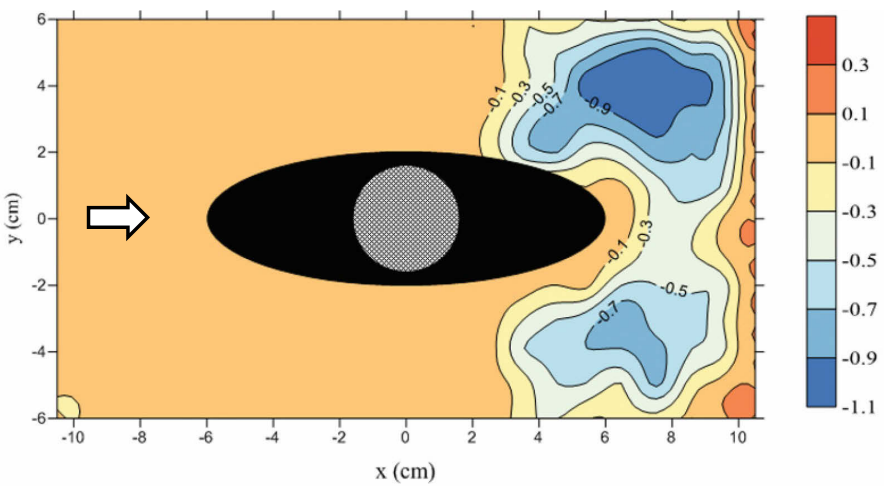

Figure $5 \mathrm{~b}$. Measured scour contours at equilibrium conditions for case $\mathrm{c}$.

Figures $5 \mathrm{a}, \mathrm{b}$ shows the measured scour contours at equilibrium conditions for case (a) and (c), respec- tively (arrow indicates flow direction). For case (b), almost no scour was observed for the adopted flow conditions (Fig. 6).

For case (a), the scour initiated at the downstream half of the pier (near the tail of pier). Within a duration of 5 minutes, the scouring reached the nose of the pier and subsequently the pile-cap also got exposed to the flow. After 15 minutes, the scouring halted at the upstream region of the pier, owing to the fact that the down flow cannot erode the exposed rigid pile-cap, but because of the flow separation and velocity increase at the pier sides, the scouring amplified at the sides of the pile-cap, thus giving rise to maximum scouring at the sides of the pile-cap. Scour depth reached equilibrium stage after 4 hours of run. Based on this observation, conclusion could be made that when the pile-cap was submerged in the sand, after sometime, it gets exposed because of erosion above it, and then the scour takes place according to the shape and overhang of the pile-cap afterwards.

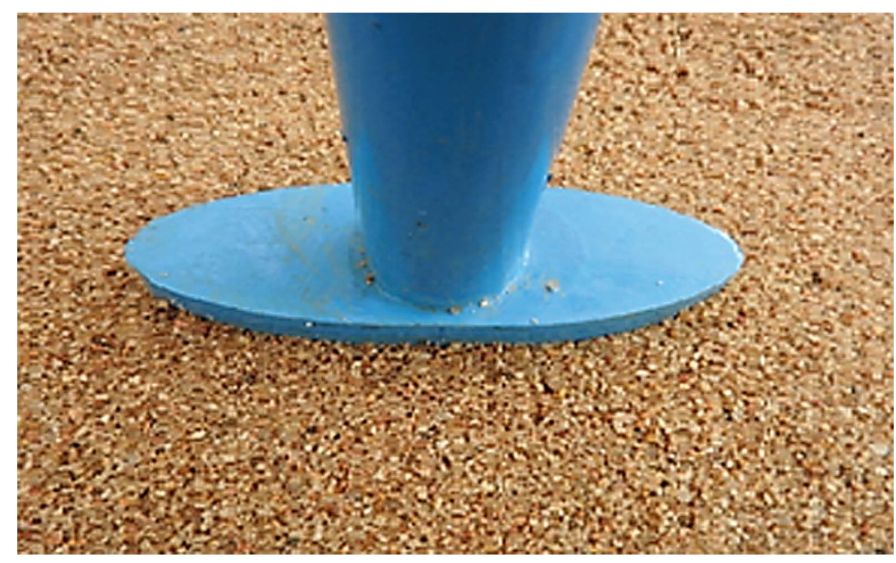

Figure 6. Photograph showing no scour in case b.

For case (b), no scour was observed at all around the pier (Fig. 6). The partially buried pile-cap acted as a scour countermeasure against bridge pier scour here, which resulted in completely no scour around thespile-cap. The elliptical shape of the pile-cap aided in the streamlining of the flow responsible for less turbulence and hence no scour.

For case (c), the scour only took place mostly in the downstream region of the pier. The scour in case (c) was still more than that in case (b) and less than that in case (a). So, it can be established that case (b) is the most suitable pile-cap location in order to avoid scour around a complex pier with elliptical shaped pile-cap.

\subsection{Mean velocity profiles}

To facilitate the velocity measurements in streamwise and vertical directions, the ADV was mounted on a movable trolley kept on the flume rails. The instrument was connected to the PC for real-time visu- 
alization of the velocities, using ExploreV software (Nortek Product).

The raw velocity data collected during the experiments using ADV were post-processed to remove the spikes (noise) using phase space threshold despiking method given by Goring and Nikora (2002). The data was sorted by removing the errors with low Signal to Noise ratio (SNR) $(<15 \mathrm{~dB})$ and low correlation $(<70 \%)$ samples. This way, about 3 to $5 \%$ of the raw data was excluded. The excluded data was replaced by cubic polynomial interpolation technique. The despiked data was then further processed to find out 3 dimensional mean velocity values from the instantaneous data obtained from ADV.

The velocities were measured at six different locations on the centerline of the flume; three in the upstream region of the pier and three in the downstream region of the pier, as shown in Figure 7.

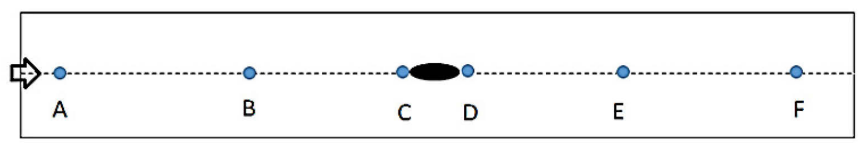

Figure 7. Locations of velocity measurements in the test section.

The locations of measurements are as follows:
A $20 \mathrm{~cm}$ upstream of pier center
B $9 \mathrm{~cm}$ upstream of pier center
C $5 \mathrm{~cm}$ upstream of pier center
D $5 \mathrm{~cm}$ downstream of pier center
E $9 \mathrm{~cm}$ downstream of pier center
F $20 \mathrm{~cm}$ downstream of pier center

The vertical mean velocity profiles for all the 3 cases at six different selected locations demonstrate the characteristic flow features upstream and downstream of the pier. Beheshti and Ashtiani (2010) gave velocity profiles around a complex pier structure with rectangular pier and pile-cap, but no study has been undertaken for other shapes of pier and pile-caps for comparative study.

Figures 8, 9 and 10 shows the stream-wise ( $\mathrm{x}$ direction), crosswise (y-direction) and vertical (zdirection) velocity profiles for the 3 cases, measured at afore-mentioned locations, respectively.

The effect of the exposed pile-cap is evident from the obtained velocity profiles. The effect of the thickness of the pile-cap (i.e. $5 \mathrm{~cm}$ ) is also clearly visible in the velocity profiles. The varying velocity zone has increased from $4-5 \mathrm{~cm}$ from case $\mathrm{b}$ to $6-7$ $\mathrm{cm}$ in case $\mathrm{c}$.

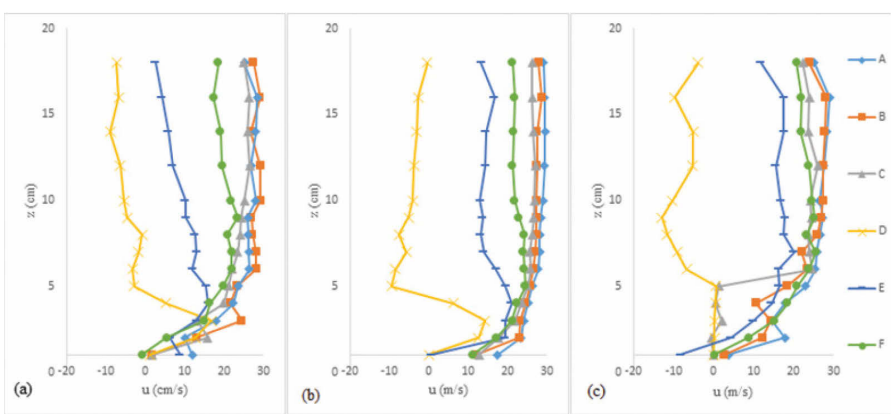

Figure 8. Stream-wise mean velocity profiles at the plane of symmetry upstream and downstream of pier for cases $a, b$ and c, respectively.

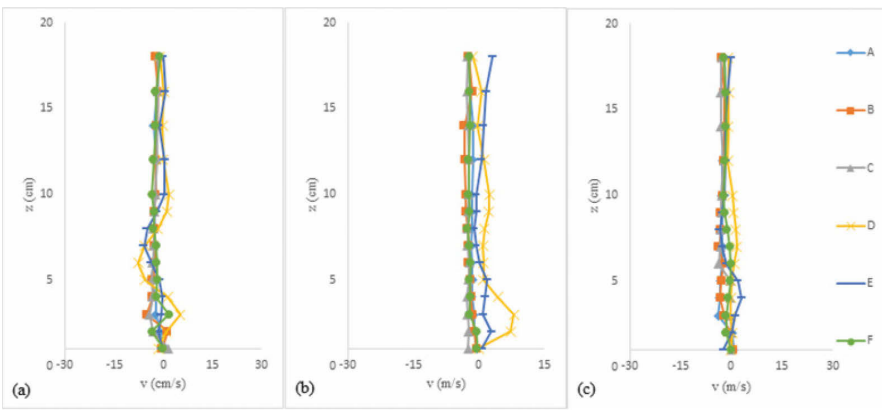

Figure 9. Lateral mean velocity profiles at the plane of symmetry upstream and downstream of pier for cases $a, b$ and $c$, respectively.

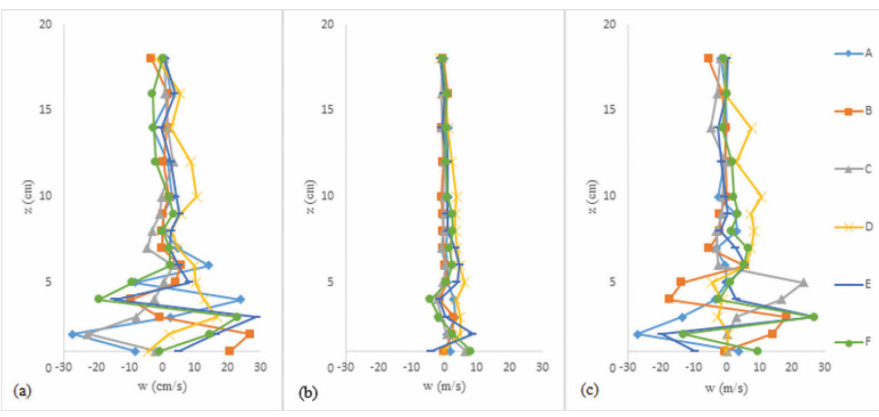

Figure 10. Vertical mean velocity profiles at the plane of symmetry upstream and downstream of pier for cases $a, b$ and $c$, respectively.

In case a, the stream-wise velocities (fig. 8(a)) on the upstream of the pier followed logarithmic law, but it was observed that the velocities decreased as the flow approached the pier. On the downstream side of the pier, a backward flow was observed. At $20 \mathrm{~cm}$ downstream of the pier, the velocity profiles seemed to regain back its original logarithmic nature. The lateral velocity profiles (Fig. 9 (a)) show very low flow velocity values far upstream of the pier. Near the nose of the pier, the velocities reached near zero velocities. But, at the downstream side of the pier, the lateral velocities show an oscillatory behavior, contributed by the existence of the Horse shoe Vortex severity on the downstream of pier. Again, at $20 \mathrm{~cm}$ away from the pier tail, the velocities regained their original values. The vertical velocity profiles (Fig. 10(a)) show that the velocity 
values are more or less zero from a distance of $4 \mathrm{~cm}$ from the bed till near water surface. In the $4-5 \mathrm{~cm}$ region near the bed, the velocity values show sudden and random variation, and surprisingly this variation isn't limited to near field of the pier, at far field of the pier also, this variation is observed.

In case b, the stream-wise velocity profiles (Fig. 8(b)) followed logarithmic law away from the pier. The velocities increased as they approached the pier. On the downstream side, on the other hand, the velocities are higher near to the bed as compared to the velocities above the pile-cap region but interestingly, the vertical velocity profile (Fig. 10(b)) is almost constant with near zero velocity. It is assumed that since the vertical velocity profile is almost nonchanging, the scour initiating downward flow was non-existent because of the presence of the pile-cap. Also the exposed sides of the pile-cap lead to smooth transition of the streamlines around it leading to reduction in the severity of the horse shoe vortex mechanism, and hence no scouring in this case.

In case c, the vertical velocities (Fig. 10(c)) show variations even on the far downstream of the pier, explaining the downstream scour of the pier. The change in lateral velocities (Fig. 9(c)) is almost negligible on the upstream side of the pier, though on the downstream side, the velocities are found to be fluctuating. But, this fluctuation was not strong enough to cause any erosion around the pier. No scour was observed on the front of the pile-cap in case c, little scour on the sides of the pile-cap, and comparatively greater scour on the downstream of the pile-cap tail.

\section{DISCUSSIONS}

The purpose of this experimental study was to find out the scour pattern around the pile-cap when it is at different elevations with respect to the sand bed. Previous studies on complex piers are mostly on rectangular pile caps ignoring other shapes of the pilecap. The drive to use an elliptical pile-cap in this study was also to test its effectiveness against scour. Case $\mathrm{b}$ here resembles foundation caisson protruding above the original bed level for which Melville and Raudkivi (1996) stated that the scour depth gets increased if the caisson top level relative to the bed is kept at higher level than the sand bed, because of the fact that greater flow interferes with the pier as compared to a single column. Our observations showed a contradiction to the above stated results. But case $b$ can also be compared to the effectiveness of collar studied by Sonneville et al. (2010). They found out that a collar attached to a pier, placed on the bed level acts as an effective scour protection technique. The pile cap exposed to the flow (case b) resembles a similar configuration. Case $\mathrm{c}$ resembles an off- shore gravity based structure. Although, it will take greater time period and stronger currents to happen.

\section{CONCLUSIONS}

In this study, the effects of using an elliptical shaped pile-cap in reducing scour depth at various pile-cap elevations with respect to the sand bed was investigated. The mean velocity data were examined to determine the relative importance of flow on scour depth as well as the effect of various components of the pier. Based on the experimental results, the following conclusions are drawn from the present study, as compared to existing literature:

- Use of elliptical shape of pile-cap can act as an effective way of reducing scour around a pier.

- For pile-cap completely buried in the sand, maximum scour depth was witnessed for the given discharge.

- Best elevation for the elliptical pile-cap to be placed is partially buried in the sand. Null or very slight scour was observed for this elevation. So, to dampen the vortex mechanism around the pier, it seemed necessary for the pile-cap to be placed partially or completely over the sand bed.

- When the pile-cap was resting on the sand bed (completely exposed to the flow), there was slight scour around the pier, but interestingly the scour occurred at mostly far downstream of the pier.

\section{REFERENCES}

Akib, S. and Jahangirzadeh, A. (2014). Local scour around complex pier groups and combined piles at semi-integral bridge, J. Hydrol. Hydromech., 62(2): 108-116.

Ataie-Ashtiani, B., Baratian-Ghorghi, Z., and Beheshti, A. A. (2010). Experimental investigation of clear-water local scour of compound piers. J. Hydraulic Engineering, 6(343): 343-351.

Beheshti, A. A., and Ataie-Ashtiani, B. (2010). Experimental study of three-dimensional flow field around a complex bridge pier. J. Engineering Mechanics, 73: 143-154.

Beheshti, A. A., and Ataie-Ashtiani, B. (2016). Scour hole influence on turbulent flow field around complex bridge piers. Flow Turbulence Combust., DOI 10.1007/s10494016-9707-8

Chiew, Y. M., and Melville, B. W. (1987). Local scour around bridge piers. J. Hydraulic Research, 25(1): 15-26.

Coleman, S. E., (2005). Clearwater scour at Complex Piers. $J$. Hydraulic Engineering, 4: 330-334.

Ferraro, D., Tafarojnoruz, A., Gaudio, R. and Cardoso, A. H. (2013). Effects of pile cap thickness on the maximum scour depth at a complex pier. J. Hydraulic Engineering, 704: $482-491$.

Goring D.G., Nikora V., (2002). Despiking acoustic Doppler Velocimeter data. J Hydraulic Engineering, 128(1):117126. 
Hydraulic Eng. Circular (HEC-18) manual, (2001). Evaluating Scour at Bridges. Federal Highway Administration (FHWA), USA.

Melville, B.W., Raudkivi, A. J. (1996). Effect of foundation geometry on bridge pier scour. J. Hydraulic Engineering, 4(203): 203-209.

Melville, B. W., Coleman, S.E. and Priestley, S., (2006). Local scour at complex piers. World Environmental and Water Resource Congress, ASCE.

Miller, M. C., McCave, I. N. and Komar, P. D., (1977). Threshold of sediment motion under unidirectional currents. Sedimentology, 24: 507-527.

Moreno, M., Maia, R. and Couto, L., (2015). Effects of relative column width and pile-cap elevation on local scour depth around complex piers. J. Hydraulic Engineering, ASCE.

Shen H.W., Schneider, V.R. and Karaki, S.S. (1969), Local scour around bridge piers. Proc ASCE, J Hydraulic Div.; 95 (HY6): 1919-1940.

Sonneville B.de, Rudolph, D., Raaijmakers, T.C., (2010), Scour reduction by collars around offshore monopiles. Fifth International Conference on Scour and Erosion, San Francisco, California, United States 2010. 